\title{
Intolerance of uncertainty is associated with reduced attentional inhibition in the absence of direct threat
}

Article

Accepted Version

Creative Commons: Attribution-Noncommercial-No Derivative Works 4.0

Morriss, J. and McSorley, E. (2019) Intolerance of uncertainty is associated with reduced attentional inhibition in the absence of direct threat. Behaviour Research and Therapy, 118. pp. 16. ISSN 0005-7967 doi:

https://doi.org/10.1016/j.brat.2019.03.011 Available at https://centaur.reading.ac.uk/82991/

It is advisable to refer to the publisher's version if you intend to cite from the work. See Guidance on citing.

To link to this article DOI: http://dx.doi.org/10.1016/j.brat.2019.03.011

Publisher: Elsevier

All outputs in CentAUR are protected by Intellectual Property Rights law, including copyright law. Copyright and IPR is retained by the creators or other copyright holders. Terms and conditions for use of this material are defined in the End User Agreement.

www.reading.ac.uk/centaur 
Central Archive at the University of Reading

Reading's research outputs online 


\section{Accepted Manuscript}

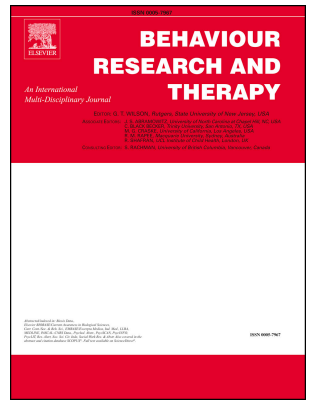

Intolerance of uncertainty is associated with reduced attentional inhibition in the absence of direct threat

Jayne Morriss, Eugene McSorley

PII: S0005-7967(19)30052-X

DOI: $\quad$ https://doi.org/10.1016/j.brat.2019.03.011

Reference: BRT 3388

To appear in: Behaviour Research and Therapy

Received Date: 31 July 2018

Revised Date: 5 March 2019

Accepted Date: 18 March 2019

Please cite this article as: Morriss, J., McSorley, E., Intolerance of uncertainty is associated with reduced attentional inhibition in the absence of direct threat, Behaviour Research and Therapy (2019), doi: https://doi.org/10.1016/j.brat.2019.03.011.

This is a PDF file of an unedited manuscript that has been accepted for publication. As a service to our customers we are providing this early version of the manuscript. The manuscript will undergo copyediting, typesetting, and review of the resulting proof before it is published in its final form. Please note that during the production process errors may be discovered which could affect the content, and all legal disclaimers that apply to the journal pertain. 
Intolerance of uncertainty is associated with reduced attentional inhibition in the absence of direct threat

Jayne Morriss ${ }^{1}$

Eugene McSorley ${ }^{2}$

${ }^{1}$ Centre for Integrative Neuroscience and Neurodynamics, School of Psychology and Clinical Language Sciences, University of Reading, Reading, RG6 6AL, United Kingdom.

${ }^{2}$ School of Psychology and Clinical Language Sciences, University of Reading, Reading, RG6 6AL, United Kingdom. 


\begin{abstract}
Intolerance of uncertainty (IU) is a dispositional tendency to find uncertain situations aversive and anxiety-provoking. There is limited understanding as to how IU may bias attention to uncertainty in the absence of direct threat. Here we examined the extent to which uncertain distractors and individual differences in IU impacted eyemovements during an attentional capture task. Participants were asked to move their eyes towards a target, whilst ignoring an array of distractors. An additional distractor could appear before or after the target in a near or far location from the target. We observed high IU individuals to display fewer first saccades to the target in all conditions. The results were specific to IU, over trait anxiety. Overall, these results suggest that IU modulates attention to uncertainty in the absence of direct threat. Such findings inform the conceptualization of IU and its relation to psychopathology.
\end{abstract}

Keywords: attention, inhibition, eye-movements, intolerance of uncertainty, anxiety 


\section{Introduction}

Individuals differ in the way in which they perceive and experience uncertainty. Intolerance of Uncertainty (IU) can be defined as a dispositional tendency to find uncertain situations aversive and anxiety provoking. A modern definition of IU has recently been put forward: 'IU is an individual's dispositional incapacity to endure the aversive response triggered by the perceived absence of salient, key, or sufficient information, and sustained by the associated perception of uncertainty' (Carleton, 2016, p. 31). Carleton (2016) suggests that IU may stem from a fundamental fear of the unknown. Historically, clinicians developed the self-reported IU scale (Freeston, Rhéaume, Letarte, Dugas, \& Ladouceur, 1994) to assess individual differences in uncertainty-induced anxiety related to Generalized Anxiety Disorder. However, IU has been identified as a transdiagnostic factor that cuts across many anxiety and mood disorders (Carleton, Fetzner, Hackl, \& McEvoy, 2013; Gentes \& Ruscio, 2011; McEvoy \& Mahoney, 2012).

A recent and emerging debate is whether IU can modulate psychological mechanisms in the absence of direct threat (Carleton, 2016; Pepperdine, Lomax, \& Freeston, 2018; Shihata, McEvoy, Mullan, \& Carleton, 2016). The majority of research has examined IU in relation to uncertain threat (Grupe \& Nitschke, 2013; Tanovic, Gee, \& Joormann, 2018). For example, during contexts with uncertain threat high IU individuals display heightened physiological responding and neural activity to both threat and safety cues (Chin, Nelson, Jackson, \& Hajcak, 2016; Dunsmoor, Campese, Ceceli, LeDoux, \& Phelps, 2015; Morriss, Christakou, \& Van Reekum, 2015, 2016; Morriss, Macdonald, \& van Reekum, 2016). Moreover, high IU individuals have been found to exhibit attentional biases to uncertain threatening 
distractors, indexed by larger landing position deviation of the eyes towards angry face distractors (Morriss et al., 2017).

However, a handful of studies have also found IU to impact psychological processes in the absence of direct threat (Fergus, Bardeen, \& Wu, 2013; Fergus \& Carleton, 2016; Gorka, Nelson, Phan, \& Shankman, 2016; Pepperdine et al., 2018). For example, experimental data show that high IU individuals are slower to react when there are multiple cues (Fergus \& Carleton, 2016) and show facilitated engagement with stimuli that convey uncertainty e.g. words related to uncertainty (Fergus et al., 2013). In addition, using a variety of scenarios, Pepperdine et al. (2018) observed IU to be associated with negative perceptions of uncertainty for all types of potential outcomes (e.g. negative, positive, none). Furthermore, in rewarding contexts with no chance of loss (threat), high IU individuals display greater engagement with uncertain reward (Gorka, Nelson, Phan, \& Shankman, 2016).

The findings outlined above suggest that IU operates under uncertain contexts with and without direct threat. Notably, research identifying IU-related biases in the absence of threat has primarily been attentional (Fergus et al., 2013; Fergus \& Carleton, 2016). However, there is limited understanding as to which attentional processes are modulated by IU in the absence of direct threat. The majority of the literature on attentional bias and threat has focused on using the selfreported Trait Anxiety measure (for review see Cisler \& Koster, 2010). Therefore, to test the specificity of IU on attentional biases to uncertainty in the absence of direct threat it is important to compare and contrast against the commonly used Trait Anxiety measure. Identifying attentional processes that are specifically modulated by IU will be useful for developing theoretical models of IU in relation to threat presence 
or absence, as well as determining potential diagnosis and treatment targets for IUbased psychopathology (Shihata, McEvoy,Mullan, \& Carleton, 2016).

Here we propose to build on previous research to assess how IU may alter attentional processes during uncertainty in the absence of direct threat using an attentional capture task in combination with eye-tracking technology. In the current study we use a typical attentional capture task, which included elements of both spatial and temporal uncertainty (Theeuwes, De Vries, \& Godijn, 2003; Theeuwes, Kramer, Hahn, Irwin, \& Zelinsky, 1999). An array of four grey coloured circles are presented. Then, one circle remains grey and all the others change to red circles. The circle that remains grey is randomly allocated and acts as target. In this condition, there is some uncertainty as the location of the grey circle relative to the other red circles is spatially uncertain. On some of the trials, another red distractor circle can appear before or after the target in a near or far location from the target. In these conditions, there is more uncertainty, as the location of the grey circle relative to the other red circles is spatially uncertain and the timing of a new red distractor is temporally uncertain. The participant's goal is to make a saccade (eye-movement) to the target, whilst ignoring the other distractors. In these tasks, participants typically make fewer first saccades with longer latencies to the target due to the abrupt onset of the distractor (i.e. the eyes move to the distractor instead of the target) (Theeuwes, De Vries, \& Godijn, 2003; Theeuwes, Kramer, Hahn, Irwin, \& Zelinsky, 1999). Furthermore, fewer first saccades with longer latencies to the target are found when the presentation of the target and distractor are closer together: (1) spatially and (2) temporally (Theeuwes, Kramer, Hahn, Irwin \& Zelinsky, 1999).

In the current study we focus on saccade count and saccade latency measures, which measure spatial and temporal aspects of attention respectively 
(McSorley \& Morriss, 2015; McSorley, Morriss, \& van Reekum, 2016; Morriss, McSorley, \& van Reekum, 2017). Based on previous work (Theeuwes, De Vries, \& Godijn, 2003; Theeuwes, Kramer, Hahn, Irwin, \& Zelinsky, 1999), we predicted all participants to have: (1) fewer first saccades with longer latencies directed to the target during the near distractor condition, compared to the far and no distractor conditions, and (2) fewer first saccades with longer latencies directed to the target when distractors were presented before the target, compared to after the target.

We also expected individual differences in IU to account for substantial variance in the number of first saccades and their latencies, in line with our previous eyetracking work in IU during uncertain threat (Morriss et al., 2017). We expected higher IU to be associated with fewer first saccades and longer latencies to the target during the near distractor condition, compared to the far and no distractor conditions. Furthermore, we predicted that higher IU would be related to fewer first saccades and longer first saccade latencies to the target when distractors were presented before the target, compared to after the target. Lastly, we expected effects of task uncertainty on first saccades and saccade latency to be specific to IU over and above the Trait Anxiety measure (Spielberger, Gorsuch, Lushene, Vagg, \& Jacobs, 1983). To keep in line with current transdiagnostic research and theory, we also examined the shortened IUS-12, and the prospective (P-IU) and inhibitory (I-IU) subscales (Carleton, Norton, \& Asmundson, 2007), which can be derived from the full IU scale.

\section{Method}

\section{Participants}


Fifty-nine volunteers $(M$ age $=23.47, S D$ age $=4.57 ; 32$ females and 27 males $)$ took part. All observers had normal, or corrected to normal vision and were recruited through adverts placed around the campus area and word of mouth. All participants gave their informed consent prior to inclusion and were paid £5 for their time. The procedure received a favorable opinion from the University of Reading Research Ethics Committee.

\section{Questionnaires}

Self-reported IU (Freeston et al., 1994) and the State-Trait Anxiety Inventory (STAI) (Spielberger et al., 1983) were collected. The IU measure consisted of 27 items, example items included "I must get away from all uncertain situations" and "Uncertainty makes me uneasy, anxious, or stressed". To check the specificity of IU, we compared it with the commonly used Trait Anxiety subscale from the STAI measure, consisting of 20 items.

\section{Apparatus}

Eye movements were recorded using an Eyelink II eye-tracker with a sampling rate of $500 \mathrm{~Hz}$ (SR Research). Stimuli were presented on a 21 " colour monitor with a refresh rate of $75 \mathrm{~Hz}$ (DiamondPro, Sony). Head movements were constrained with a chin-rest at a viewing distance of $57 \mathrm{~cm}$. The eye-tracker was calibrated using a standard 9 point grid at the start of the experiment.

\section{Stimuli}


A cross ('+') 0.5 deg of visual angle in length was shown as a fixation marker. The experimental displays consisted of filled circles each 1 deg of visual angle in diameter and presented on a black background. Circles were either grey or red.

\section{Design}

The initial screen consisted of a fixation cross and four grey circles displayed 9 deg of visual angle from the fixation cross on the oblique axes. After a random display duration of $800-1200 \mathrm{~ms}$, three of the circles turned red leaving one circle grey, and this remained on screen for a display duration of 1 second. Participants were required to saccade to the remaining grey circular target. On $66 \%$ of trials a new red circle was also displayed. This was presented on one of the principal axes 9 deg of visual angle horizontally or vertically with respect to the fixation cross, either $75 \mathrm{~ms}$ prior to or $75 \mathrm{~ms}$ after the circles change. The new stimulus was near or far from the target in a clockwise or counter-clockwise direction in an equivalent proportion of trials (for example, see Fig 1). Overall there were 96 trials per participant. 32 trials contained no new stimulus. The 64 remaining trials contained the new stimulus with 12 trials per location relative to the target: near clockwise, far clockwise, near counter-clockwise, far counter-clockwise; and 6 per stimulus onset asynchrony (new red circle shown $75 \mathrm{~ms}$ before or after the grey target is revealed). Results are presented collapsed across the direction of the new red stimulus (clockwise and counter-clockwise of the target) giving 12 trials per condition.

\section{Procedure}


Participants were instructed to "saccade to remaining grey circle" to "ignore the new red stimulus". Once comfortable with the task, the eye tracker was fitted and a calibration procedure was performed before they carried out the task.

\section{Eye-tracking Measures}

Saccade start and endpoints were identified using a $22 \%$ s velocity and $8000 \%$ s2 acceleration criteria. The amplitude and latency of the saccade were extracted for the first saccade response. First saccades were excluded from further analysis if saccade amplitude was less than 2 deg of visual angle $(0.14 \%)$ or if response latency was quicker than $80 \mathrm{~ms}$ (classified as an anticipatory saccade) or slower than $800 \mathrm{~ms}$ (in these cases the saccade is taken as having not been driven by the experimental display) (0.006\%). Saccade counts and average saccade latencies are reported.

[Figure 1 near here]

\section{Analyses}

The analyses were conducted using the mixed procedure in SPSS 21.0 (SPSS, Inc; Chicago, Illinois). We conducted separate multilevel models on first saccade count and first saccade latency by entering Distractor (none, near, far) at level 1 and individual subjects at level 2, with IU, and STAI entered as individual difference predictor variables in no particular order. Furthermore, to examine the impact of distractor type and time we included additional multilevel models on first saccade count and first saccade latency. We entered Distractor (near, far) and Time (-75 ms, $+75 \mathrm{~ms})$ at level 1 and individual subjects at level 2, with IU, and STAI 
entered as individual difference predictor variables. For exploratory purposes, additional models on first saccade count and first saccade latency with IUS-12 and STAI, as well as P-IU, I-IU and STAI were included. For all models, we used a diagonal covariance matrix for level 1. Random effects included a random intercept for each individual subject, where a variance components covariance structure was used. Fixed effects included Distractor or Distractor and Time. We used maximum likelihood estimators.

We report the specificity of IU with respect to STAI where a significant interaction of IU with Distractor, Time or Distractor x Time was observed. Then, we perform follow-up pairwise comparisons on the estimated marginal means, adjusted for the predictor variables (IU, STAI). Any interaction with IU was followed up with pairwise comparisons of the means between the conditions for IU estimated at the specific values of + or -1 SD of mean IU. These data are estimated from the multilevel model of the entire sample, not unlike performing a simple slopes analysis in a multiple regression analysis (Morriss, MacDonald, \& van Reekum, 2016; Morriss, McSorley \& van Reekum, 2017).

\section{Results}

\section{Questionnaires}

Similar distributions and internal reliability of scores were found for the anxiety measures: $I U(M=67.80, S D=17.37$, range $=29-100, \alpha=.93)$; Trait Anxiety $(M=$ $42.10, S D=10.78$, range $=24-60, \alpha=.92) ;$ IUS $-12(M=31.03, S D=8.25$, range $=13-$ $46, \alpha=.87), \mathrm{P}-\mathrm{IU}(\mathrm{M}=19.74, \mathrm{SD}=5.30$, range $=8-31, \alpha=.82)$ : and $\mathrm{I}-\mathrm{IU}(\mathrm{M}=11.28$, $\mathrm{SD}=3.74$, range $=5-21, \alpha=.78)$. 


\section{Eye-tracking Outcomes}

First saccade count. We found a main effect of distractor type on first saccade count [Distractor: $F(1,224.382)=35.959, p<.001$ ] (see Table 1). Follow up pairwise comparisons revealed more first saccades to the target during the no distractor, followed by the far distractor and near distractor conditions, p's $<.050$. Low IU was associated with more first saccades to the target for each distractor condition, over high IU [Distractor $x$ IU: $F(1,59)=5.657, p=.002]$ (see Fig 2). A similar pattern was observed for first saccade count and STAI but it was not significant [Distractor $\mathrm{x}$ STAI: $F(1,59)=2.447, p=.073]$. No other significant interactions for first saccade count were observed for distractor type and IUS-12, P-IU, and I-IU, $\max F=1.515, p=$ 217.

There were more first saccade to the target when the distractors were presented after the target, compared to before the target [Time:

$F(1,159.292)=44.351, p<.001]$ (see Table 1). Furthermore, there were more first saccades to the target when the distractor was far and after the target, compared to when the distractor was near and after the target [Distractor $\mathrm{x}$ Time:

$F(1,159.292)=5.701, p=.018]$. No other significant interactions for first saccade count were observed for distractor $\mathrm{x}$ time and IU,STAI, IUS-12, P-IU, and I-IU, max $F=$ $3.814, p=.053$.

First saccade latency: We found a main effect of distractor type on first saccade latency [Distractor: $F(1,58.320)=44.903, p<.001]$ (see Table 1). Follow up pairwise comparisons showed that the first saccade latency was shorter for the no distractor, versus near and far distractors, $p$ 's $<.001$. The first saccade latency for near and far distractors was not significantly different, $p=.500$. No other significant interactions 
for first saccade latency were observed for distractor type and IU,STAI, IUS-12, P-IU, and $\mathrm{I}-\mathrm{IU}, \max F=2.375, p=.102$.

First saccade latencies were shorter for distractors presented after the target, compared to distractors presented before the target [Distractor $\mathrm{x}$ Time:

$F(1,169.499)=6.052, p=.015]$. No other significant interactions for first saccade latency were observed for distractor $x$ time and IU,STAI, IUS-12, P-IU, and I-IU, max $F=3.356, p=.069$.

[Table 1 near here]

[Figure 2 near here]

\section{Relationships between IU items and total first saccade count}

Additional posthoc analyses were conducted to examine the relationship between each IU item and total first saccade count across conditions (none, near and far). We collapsed first saccade count across all conditions, as similar IU effects were observed across all conditions. The majority of the IU items were normally distributed (i.e. skewness and kurtosis values between 2 and -2). However, a few of the items displayed skew over 1 (item 2 and 23) and kurtosis over 1 (items 2, 17, 20 and 24). Due to some of the items having mild skew and kurtosis, as well as the Likert scale data for each item being ordinal, we conducted Spearmans Rho correlations between each full scale IU item and total first saccade count ${ }^{1}$. The results revealed significant negative correlations between IU items 13, 14, 24 and 25 with total first saccade count, $r$ s $(57)>.264, p<.05$ (see Table 2$)$. Thus, a higher score on these

\footnotetext{
${ }^{1}$ The results were similar when conducting correlations using Pearson's tests. IU items 3 and 7 moved from trend to significance, $p$ 's <.05, whilst IU items 13 and 14 moved from significance to trend ( $p$ 's < .084).
} 
items was associated with fewer first saccade counts. IU items, 13, 14, and 24 are from the full IU scale, whilst IU item 25 is included in both the full IU scale and IUS12.

[Table 2 near here]

\section{Discussion}

In the present study, we show that self-reported IU is associated with reduced attentional inhibition in the absence of direct threat. The IU findings were specific and predicted variance over and above that shared with the commonly used Trait Anxiety measure. Taken together, these results further our understanding of how IU modulates attention in the absence of direct threat, which will be relevant to theoretical models of IU (Carleton, 2016).

For the attentional capture task, we found that in general participants exhibited a greater number of first saccades with shorter latencies to the target in the no distractor condition, followed by far and near distractor conditions (Theeuwes, De Vries, \& Godijn, 2003; Theeuwes, Kramer, Hahn, Irwin, \& Zelinsky, 1999). Importantly, high IU was associated with fewer first saccades to the target, regardless of the type of distractor or time of distractor. IU was not found to predict saccade latency. These results suggest that the distractors interfered with spatial and temporal attention in all participants, as indexed by first saccade count and latency respectively. However, for high IU individuals, the distractors interfered more with spatial attention, as measured by first saccade count. The IU-related findings observed here are in line with previous research where high IU has been shown to 
be associated with slower reaction times when there are multiple cues and facilitated engagement with uncertain word stimuli embedded amongst other stimuli (Fergus, Bardeen, \& Wu, 2013; Fergus \& Carleton, 2016). In addition, this finding sits alongside recent eye-tracking work where high IU individuals were found to exhibit difficulties inhibiting unpredictable angry faces (Morriss et al., 2017). In relation to the IU literature as a whole (for review see Tanovic et al., 2018), the current finding provides further evidence that IU is capable of modulating attention during uncertain contexts in the absence and presence of threat.

The results from this study suggest that individuals high in IU have difficulty with spatial attention, particularly when there is uncertainty. Although, an alternative explanation could be that individuals high in IU have a difficulty with attention globally as they displayed fewer first saccades across all conditions. Notably, all the conditions contained an element of spatial uncertainty, even the no distractor condition, as participants were unable to predict the location of the target. Therefore, a more plausible explanation would be that individuals high in IU display difficulty with spatial attention across contexts, particularly uncertain ones. This interpretation is in line with previous findings that have shown individuals high in IU to only exhibit attentional biases to distractors in contexts with greater spatial uncertainty (Morriss et al., 2017). To understand the role of IU on attention further, future research should focus on manipulating different levels of spatial and temporal uncertainty.

The empirical evidence presented here supports recent IU theory. The current study shows that IU can operate in the absence of direct threat. Carleton (2016) suggests that IU may stem from the fear of the unknown. Therefore, uncertainty in itself is aversive enough to trigger particular cognitive, emotional and behavioural responses. This is an important theoretical distinction and marks a change in the 
way the field understands IU-related psychopathology, as the majority of previous research has focused on uncertain threat (Grupe \& Nitschke, 2013; Tanovic, Gee, \& Joormann, 2018). More empirical research is needed to clarify why uncertainty in the absence of threat is aversive (Shihata, McEvoy, Mullan, \& Carleton, 2016). For example, it will be important to identify whether distinct psychological mechanisms are modulated by uncertainty and threat differently e.g. attentional inhibition versus associative learning. This will be important for determining whether a given mechanism is: (1) equally modulated by uncertainty in the absence and presence of threat, or (2) linearly modulated by the uncertainty and threat level. The revelation of these aspects of IU will help pave the way for the development of appropriate transdiagnostic treatments for IU-related psychopathology.

Significant effects of the IUS-12, P-IU or I-IU on the eyetracking measures were not observed in the current experiment, despite the results being in a similar direction to the full IU scale. Moreover, it was revealed that more IU items from the full scale, compared to the IUS-12 predicted total first saccade target count. This is interesting given that current research examining the IU questionnaire has preferred the IUS-12, given its consistent and robust psychometrics (Carleton, Norton, \& Asmundson, 2007; Hong \& Lee, 2015). The full IU scale was originally devised to examine generalized anxiety disorder (Dugas, Gagnon, Ladouceur, \& Freeston, 1998) and contains other item content which may be less specific to uncertainty (Carleton, Norton, \& Asmundson, 2007). Notably, the IU items that significantly correlated with the total first saccade target count were related to confidence, motivation and sleep. Given these findings, it is possible that relationships between IU and attention may be influenced by other latent constructs. Further work is 
needed to disentangle the role of the full IU scale versus IUS-12 and its subscales on attention.

The present study had a few limitations which should be addressed in future research to assess the robustness and generalizability of the findings reported here. The experiment was conducted on an unselected community sample. Further work should aim to replicate the experiment in different laboratories and populations, to examine how common the effect of IU on attention is across community samples, and to parcel out which clinical samples it may be most relevant for.

In conclusion, individual differences in IU predicted attentional inhibition of uncertain distractors in the absence of threat, over and above Trait Anxiety. Importantly, these results highlight an opportunity for further research to examine how IU modulates other psychological processes in the absence/presence of different levels of uncertainty and threat. 


\section{Acknowledgments}

The authors wish to thank Emily Eley-Rutter and Louis Williams for their help in data collection. This research was funded by an Undergraduate Research Opportunity Placement by the University of Reading. 


\section{Disclosure Statement}

The authors state no conflict of interest. 


\section{References}

Carleton, R. N. (2016). Into the unknown: A review and synthesis of contemporary models involving uncertainty. Journal of Anxiety Disorders, 39, 30-43.

Carleton, R. N., Fetzner, M. G., Hackl, J. L., \& McEvoy, P. (2013). Intolerance of Uncertainty as a Contributor to Fear and Avoidance Symptoms of Panic Attacks. Cognitive Behaviour Therapy, 42(4), 328-341.

Carleton, R. N., Norton, M. P. J., \& Asmundson, G. J. (2007). Fearing the unknown: A short version of the Intolerance of Uncertainty Scale. Journal of anxiety disorders, 21(1), 105-117.

Cisler, J. M., \& Koster, E. H. (2010). Mechanisms of attentional biases towards threat in anxiety disorders: An integrative review. Clinical psychology review, 30(2), 203-216.

Chin, B., Nelson, B. D., Jackson, F., \& Hajcak, G. (2016). Intolerance of uncertainty and startle potentiation in relation to different threat reinforcement rates. International Journal of Psychophysiology, 99, 79-84.

Dugas, M. J., Gagnon, F., Ladouceur, R., \& Freeston, M. H. (1998). Generalized anxiety disorder: A preliminary test of a conceptual model. Behaviour Research and Therapy, 36(2), 215-226.

Dunsmoor, J. E., Campese, V. D., Ceceli, A. O., LeDoux, J. E., \& Phelps, E. A. (2015). Novelty-facilitated extinction: providing a novel outcome in place of an expected threat diminishes recovery of defensive responses. Biological Psychiatry, 78(3), 203-209.

Fergus, T. A., Bardeen, J. R., \& Wu, K. D. (2013). Intolerance of uncertainty and uncertainty-related attentional biases: evidence of facilitated engagement or disengagement difficulty? Cognitive Therapy and Research, 37(4), 735-741. 
Fergus, T. A., \& Carleton, R. N. (2016). Intolerance of uncertainty and attentional networks: Unique associations with alerting. Journal of Anxiety Disorders, 41, $59-64$.

Freeston, M. H., Rhéaume, J., Letarte, H., Dugas, M. J., \& Ladouceur, R. (1994). Why do people worry? Personality and Individual Differences, 17(6), 791-802.

Gentes, E. L., \& Ruscio, A. M. (2011). A meta-analysis of the relation of intolerance of uncertainty to symptoms of generalized anxiety disorder, major depressive disorder, and obsessive-compulsive disorder. Clinical Psychology Review, 31(6), 923-933.

Gorka, S. M., Nelson, B. D., Phan, K. L., \& Shankman, S. A. (2016). Intolerance of uncertainty and insula activation during uncertain reward. Cognitive, Affective, \& Behavioral Neuroscience, 16(5), 929-939.

Grupe, D. W., \& Nitschke, J. B. (2013). Uncertainty and anticipation in anxiety: an integrated neurobiological and psychological perspective. Nature Reviews Neuroscience, 14(7), 488-501.

Hong, R. Y., \& Lee, S. S. (2015). Further clarifying prospective and inhibitory intolerance of uncertainty: Factorial and construct validity of test scores from the Intolerance of Uncertainty Scale. Psychological assessment, 27(2), 605.

McEvoy, P. M., \& Mahoney, A. E. (2012). To be sure, to be sure: Intolerance of uncertainty mediates symptoms of various anxiety disorders and depression. Behavior Therapy, 43(3), 533-545.

McSorley, E., \& Morriss, J. (2015). What you see is what you want to see: Motivationally relevant stimuli can interrupt current resource allocation. Cognition and Emotion, 1-7. 
McSorley, E., Morriss, J., \& van Reekum, C. M. (2016). Eye spy with my little eye: motivational relevance of visual stimuli guide eye-movements at different processing stages. Biological Psychology.

Morriss, J., Christakou, A., \& Van Reekum, C. M. (2015). Intolerance of uncertainty predicts fear extinction in amygdala-ventromedial prefrontal cortical circuitry. Biology of Mood \& Anxiety Disorders, 5(1), 1.

Morriss, J., Christakou, A., \& Van Reekum, C. M. (2016). Nothing is safe: Intolerance of uncertainty is associated with compromised fear extinction learning. Biological Psychology, 121, 187-193.

Morriss, J., Macdonald, B., \& van Reekum, C. M. (2016). What Is Going On Around Here? Intolerance of Uncertainty Predicts Threat Generalization. PloS one, 11(5), e0154494.

Morriss, J., McSorley, E., \& van Reekum, C. M. (2017). I don't know where to look: the impact of intolerance of uncertainty on saccades towards non-predictive emotional face distractors. Cognition and Emotion, 1-10.

Pepperdine, E., Lomax, C., \& Freeston, M. (2018). Disentangling Intolerance of Uncertainty and Threat Appraisal in Everyday Situations. Journal of Anxiety Disorders.

Shihata, S., McEvoy, P. M., Mullan, B. A., \& Carleton, R. N. (2016). Intolerance of uncertainty in emotional disorders: What uncertainties remain?. Journal of Anxiety Disorders, 41, 115-124.

Spielberger, C. D., Gorsuch, R. L., Lushene, R., Vagg, P., \& Jacobs, G. (1983). Consulting Psychologists Press, Inc. 2». Palo Alto (CA). 
Tanovic, E., Gee, D. G., \& Joormann, J. (2018). Intolerance of uncertainty: Neural and psychophysiological correlates of the perception of uncertainty as threatening. Clinical Psychology Review.

Theeuwes, J., De Vries, G.-J., \& Godijn, R. (2003). Attentional and oculomotor capture with static singletons. Perception \& Psychophysics, 65(5), 735-746.

Theeuwes, J., Kramer, A. F., Hahn, S., Irwin, D. E., \& Zelinsky, G. J. (1999).

Influence of attentional capture on oculomotor control. Journal of Experimental Psychology: Human Perception and Performance, 25(6), 1595. 


\section{Table 1.}

Summary of means (SD) for the attentional capture task

\begin{tabular}{lccccccc}
\hline \hline Measure & None & Near & Far & $\begin{array}{c}-75 \mathrm{~ms} \\
\text { Near }\end{array}$ & $\begin{array}{c}+75 \mathrm{~ms} \\
\text { Near }\end{array}$ & $\begin{array}{c}-75 \mathrm{~ms} \\
\text { Far }\end{array}$ & $\begin{array}{c}+75 \mathrm{~ms} \\
\text { Far }\end{array}$ \\
\hline Eye-tracking & & & & & & & \\
$\quad$ First saccade & 27.05 & 18.89 & 21.30 & 8.83 & 10.05 & 9.35 & 11.93 \\
$\quad$ count & $(4.93)$ & $(6.89)$ & $(6.02)$ & $(3.47)$ & $(4.37)$ & $(3.16)$ & $(3.41)$ \\
$\quad$ First saccade & 397.05 & 426.06 & 423.82 & 312.43 & 291.29 & 324.85 & 303.58 \\
latency & $(40.48)$ & $(51.60)$ & $(46.76)$ & $(117.79)$ & $(115.64)$ & $(121.45)$ & $(131.23)$ \\
& & & & & & & \\
\hline \hline
\end{tabular}

Note: First saccade count is the number of correct first saccades to the target quadrant; First saccade latency measured in milliseconds, $\mathrm{ms} ;-75 \mathrm{~ms}$ is the presentation time of the distractor before the target; $+75 \mathrm{~ms}$ is the presentation time of the distractor after the target. 
Table

2.

Spearmans Rho correlations between IU items and total first saccade count

IU item number

IU item text

$r$ values

1 Uncertainty stops me from having a firm opinion.

$-.076$

2 Being uncertain means that a person is disorganized.

.056

3 Uncertainty makes life intolerable.

$-.231 \dagger$

4 It's not fair that there are no guarantees in life.

$-.186$

5 My mind can't be relaxed if I don't know what will happen tomorrow.

$-.193$

6 Uncertainty makes me uneasy, anxious, or stressed.

$-.101$

7 Unforeseen events upset me greatly.

$-.233+$

8 It frustrates me not having all the information I need.

$-.063$

9 Uncertainty keeps me from living a full life.

$-.068$

10 One should always look ahead so as to avoid surprises.

$-.132$

A small unforeseen event can spoil everything, even with the best of planning.

12 When it's time to act uncertainty paralyzes me.

$-.164$

13 Being uncertain means that I am not first rate.

14 When I am uncertain I can't go forward.

15 When I am uncertain I can't function very well.

Unlike me, others always seem to know where they are going with their lives.

17 Uncertainty makes me vulnerable, unhappy, or sad.

18 I always want to know what the future has in store for me.

19 I hate being taken by surprise.

20 The smallest doubt stops me from acting.

21 I should be able to organize everything in advance.

22 Being uncertain means that I lack confidence.

23 I think it's unfair that other people seem sure about their future.

24 Uncertainty stops me from sleeping well.

25 I must get away from uncertain situations.

$-.289^{*}$

26 The ambiguities in life stress me.

$-.078$

27 I can't stand being undecided about my future.

$-.073$

Note: * Asterisks represent significance $p<.05$. $†$ Crosses represent trend findings $p<.1$. First saccade count is the number of correct first saccades to the target quadrant for all conditions (none, near, far) 


\section{Figure Captions}

Fig 1. Image depicting the attentional capture task. A fixation screen was shown initially consisting of a fixation cross and four grey circles. After a random display duration of between $800-1200$ milliseconds, three of the circles turned red leaving one circle grey and remained on screen for a display duration of 1 second.

Participants were required to saccade to the remaining grey circular target. Distractor conditions included: (A) None, (B) Far, (C) Near.

Fig 2. Bar graphs depicting IU estimated at + or -1 SD of mean IU (controlling for STAI) from the multilevel model analysis of first saccade counts to the target. Low IU was associated with more first saccades to the target for all distractor conditions, compared to high IU. Bars represent standard error estimated at + or - 1 SD of mean IU. 


\section{ACCEPTED MANUSCRIPT}

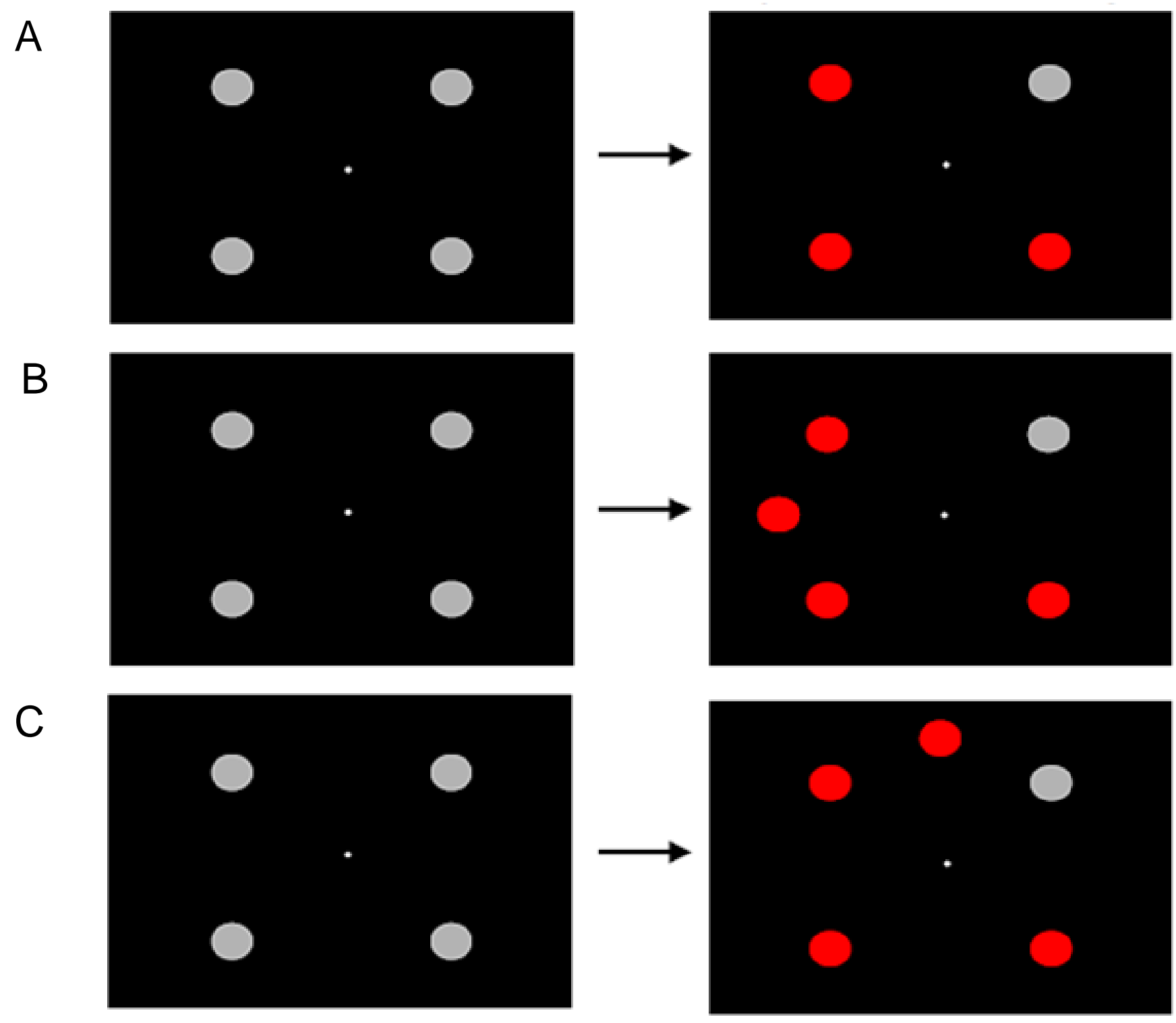




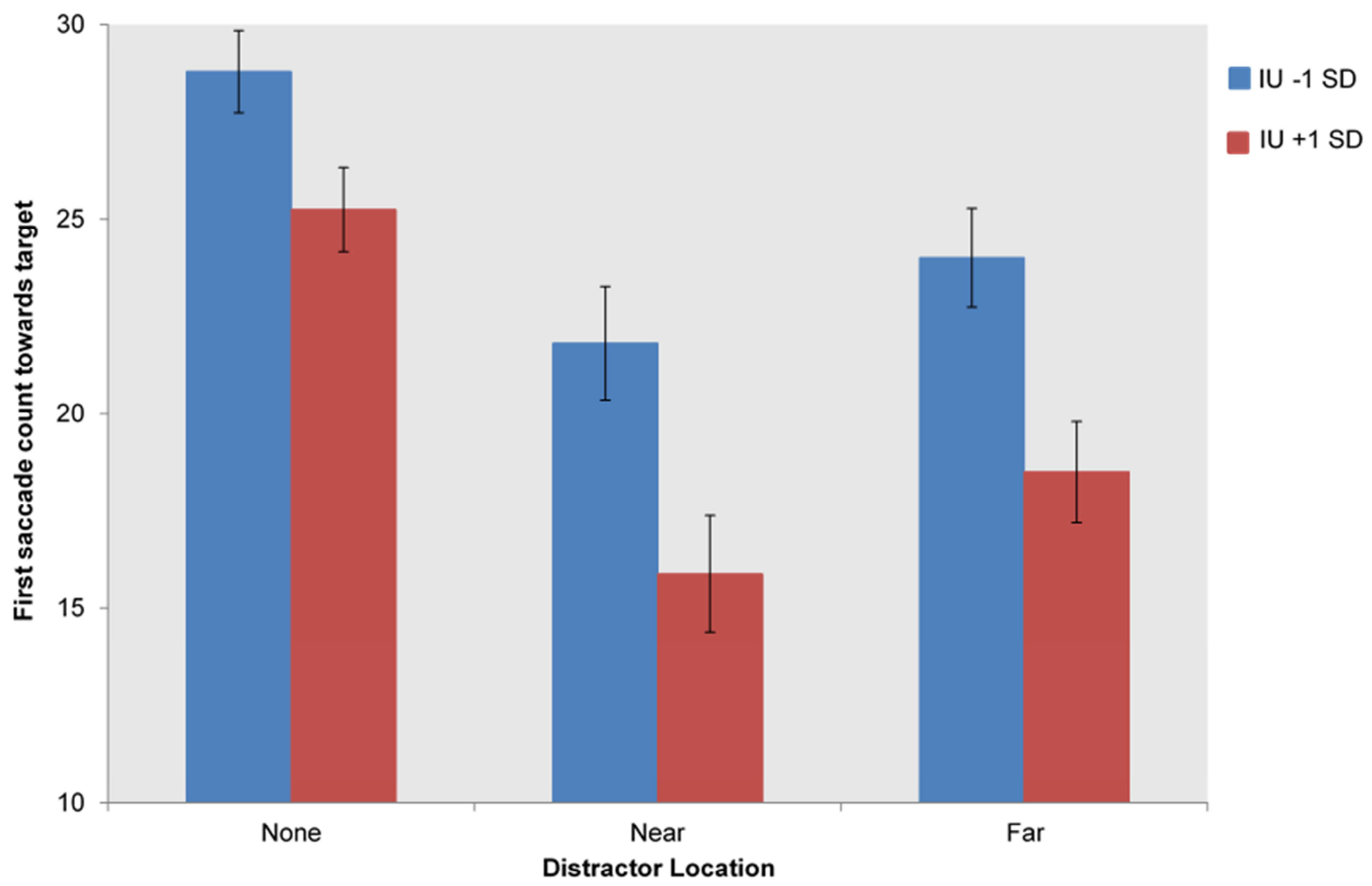




\section{Highlights}

- Intolerance of uncertainty (IU) is a tendency to find uncertainty anxietyprovoking

- We examined how IU impacts attentional capture in the absence of threat

- High IU was associated greater attentional capture to uncertain distractors

- These findings will further the conceptualisation of IU 